\title{
Ergonomics and design: traffic sign and street name sign
}

\author{
Janaina Luisa da Silva Moroni ${ }^{\mathrm{a},{ }^{*}}$ and José Luís Farinatti Aymone ${ }^{\mathrm{b}}$ \\ ${ }^{\mathrm{a}, \mathrm{b}}$ Department of Design and Graphic Expression, Federal University of Rio Grande do Sul, Designer, Integrated \\ Design Center (NID/UFRGS)Visual Design Research Group (GDV/UFRGS), Osvaldo Aranha, 99 / 408, Porto \\ Alegre, RS, Brasil.
}

\begin{abstract}
This work proposes a design methodology using ergonomics and anthropometry concepts applied to traffic sign and street name sign projects. Initially, a literature revision on cognitive ergonomics and anthropometry is performed. Several authors and their design methodologies are analyzed and the aspects to be considered in projects of traffic and street name signs are selected and other specific aspects are proposed for the design methodology. A case study of the signs of "Street of Antiques" in Porto Alegre city is presented. To do that, interviews with the population are made to evaluate the current situation of signs. After that, a new sign proposal with virtual prototyping is done using the developed methodology. The results obtained with new interviews about the proposal show the user satisfaction and the importance of cognitive ergonomics to development of this type of urban furniture.
\end{abstract}

Keywords: ergonomics, design, traffic sign

\section{Introduction}

The cognitive ergonomics seeks to understand human cognition, in a context of action and directed toward a specific goal. According to Montmolin [13], skills are inherent in all individuals. Understanding on the construction of user skills is essential for cognitive ergonomics to suggest changes in the context of a given situation, and even the design of new types of urban furniture. Aspects as perception, memory and motor response are enhanced by appropriate sensory stimulation, such as color. Sometimes the color is seen only as a subjective choice for the appearance of objects, however it should be considered as an important instrument for the satisfaction of users because it contributes to the proper functionality of traffic signs and street name signs.

\subsection{Problem description}

According to survey data based on interviews and photographs, the absence of studies of cognitive ergonomics in the design of traffic and street name signs is a major issue. Hence the choice of the visual components of sign is made in a subjective way considering its appearance. That is reason for the importance of this study, which will generate guidelines for the development of urban furniture. Therefore, to understand the literature of ergonomics, and its relationship with design, this section is divided into two topics: (1.1.1) design and ergonomics and (1.1.2) selection of user type based on anthropometry.

\subsubsection{Design and ergonomics}

According to Panero [9], anthropometry investigates the vision for a convenient visual communication system.

Therefore it can be said that the most important factors for assessment of ergonomics, in relation to

\footnotetext{
*Corresponding author. E-mail: janaina.moroni@ufrgs.br
} 
traffic and street name signs, are the biomechanics of the human body and the geometry of visual field.

Following Panero studies [9] for visual assessment of the user on a particular object, it is compared: the height of the eyes of tall and short individuals, sitting or standing, men and women; amplitude of the visual field, areas of comfortable vision and the degree to which the movement of the head and eye rotation increases the ability of vision.

Panero [9] and Dreyfuss [7] agreed to examine the user under the following aspects: (i) the visual field of the horizon line $(\mathrm{LH})$, (ii) the region of the visual cone (VC), and (iii) the person's height.

Thus, to perform signaling projects, it is necessary to understand the visual field of the various types of users: pedestrians, cyclists, drivers and passengers, in addition to observing the characteristics of these users in following situations: standing in a wheelchair, walker, crutches, visually impaired (in low, medium and high degree of vision).

With regard to visibility of signs, Dreyfuss [7] commented that color boundaries rotate according to the chosen line of sight. Thus, the variables involved are: head tilt, the limit for the identification of color in terms of tone, area, contrast, lighting, age, and irregularities of the view of respondents.

\subsubsection{Selection of user type: anthropometry}

Panero [9] collected dimensions of the various types of users to design projects. Thus, it is suggested the consultation of anthropometry before initiating a signaling project.

The selection of anthropometry depends on the user type in the region of installation of traffic and street name signs.

Since the number of people with specific characteristics is vast, it is considered, according to Panero [9], the dimensions of $5 \%$ and $95 \%$ of the population to calculate the average of individuals, according to studies in design, based on ergonomic theories. Moraes [1,2] advises not to use the average in signaling projects and says to use the lower dimension $5 \%$.

\section{Formulation of methodology}

In design there are several authors who have written design methodologies, however, it is analyzed in this work the following authors: Baxter [12] and Löbach [4].
From these authors, the following aspects have to be considered in projects of traffic and street name signs: (i) collecting data on the region of the installation of signs: culture, customs, history, climate, raw materials of the site, studies of soil type, existing types of urban furniture, types of users, types of transport systems, formats of signs, sign supports, dimensions of signs elements, colors, typography, pictogram, production processes and deployment of the signs, (ii) analysis and data discussion: positive and negative points, (iii) project development, (iv) presentation of the new proposal for local administrators of the cities, (v) presentation of the new proposal to users: residents and visitors, (vi) adjustments to the project, (vii) implementation and supervision.

To focus on ergonomics it is suggested the following steps for the development of signs: (i) evaluation of traffic and street name signs by the users, (ii) verification of positive and negative points of signs, (iii) analysis and data discussion, (iv) project development, (v) interviews with users on the new proposal of traffic and street name signs, (vi) adjustments to the project, (vii) implementation and supervision.

\section{Case study and virtual prototyping}

The case study was conducted with residents and visitors of Porto Alegre, Brazil, circulating around the "Street of Antiques". In total, 10 respondents with different profiles (height and age).

To illustrate the use of this methodology, a study group composed of adult pedestrians was selected. For real application in a project for the city, all types of users should be assessed: pedestrians, drivers, passengers, motorcyclists and cyclists of both genders. About age groups, children, adults and seniors have to be considered.

The data collection is based on the methodology of the following authors: Bauer [11], Baxter [12], Dreyfuss [7] and Löbach [4]. Initially, it began with a formal interview, through a multiple choice questionnaire and essay questions. Later, there was a photographic analysis to verify the visual field of the users in relation to the signs. After that, a new layout was created and approved by the respondents.

According to Bonsiepe [6], the design can facilitate the reception and interpretation of information to allow a more efficient action. 
Consequently the methodologies of several authors are studied, such as Baxter [12], D'Agostini and Gomes [5], Löbach [4], Dreyfuss [7], Iida [8] and made a ranking of the most common items of these methodologies.

After that, specific items of the project development of traffic and street name signs are included and the steps 3.1 to 3.8 to accomplish satisfactory results are proposed.

\subsection{Visual field}

The following aspects of the visual field are analyzed: distance from the observer, suitable visual field for recognition of color, legibility and understanding of typography and pictogram for the traffic signs (Figure 1) and street name signs (Figure 2).

First, pictures of the "Street of Antiques" were taken and then vector studies containing the visual field measures of the focus group were applied. It was used $5 \%$ of females because they are lower than men in the same percentile.

Evaluations for traffic signs were separated because some signs contain only pictograms and other pictograms with texts. Signs with pictograms are recognizable at a larger distance. However if a person is close, the reading needs the movement of the neck (Figure 1). The distant reading of traffic sings with pictograms and texts is difficult and has the same problem of readability of street name signs.

In Figure 1, the female user ( $5 \%$ percentile) with height of line of sight (B) $1.62 \mathrm{~cm}$ sees the pictogram of the traffic sign if she is 6 meters away. In this case, the viewing angle is 10 degrees with slight movement of the head back. The nearer the sign, the greater the rotation of the head back, (A) is 32 degrees.

The "No Parking" traffic sign was analyzed. It has a support base of 2 meters (C) and sign height of 40 $\mathrm{cm}$ (D).

In Figure 2, the visual field can be seen in terms of color recognition of signs. The street name sign has the same sign height of Figure 1, $40 \mathrm{~cm}$ (D), and the same height of support (C), $2 \mathrm{~m}$. Above the LH the visual field angle is $46^{\circ}$ and the following colors can be identified: blue, yellow, black and white. But there is a situation of discomfort due to movement of the head back (Figure 2).

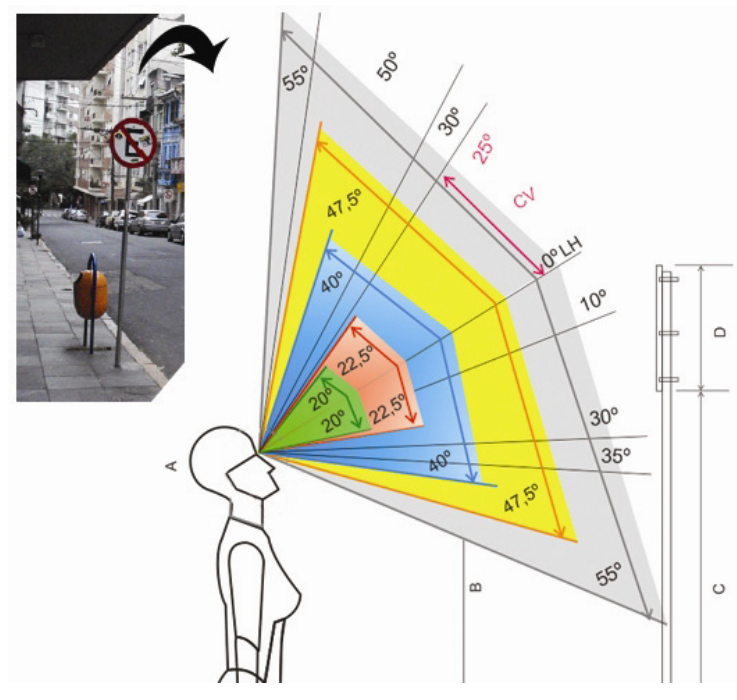

Fig. 1: Visual field of traffic sign.

To recognize the color without moving the head back, one has to view the signs at a larger distance, however the letters of the signs will get smaller.



Fig. 2: Visual field of street name sign

Figure 2 shows the street name sign with rotation of the head at 32 degrees, which indicates discomfort. To visualize the sign, eye rotation above the optimum limit of vision at 46 degrees has to be performed. Hence the acceptable limit of 30 degrees of horizon line $(\mathrm{LH})$ is exceeded with the sign. 
The visual field of recognition of colors is also analyzed. For the green color the visual field is $20^{\circ}$ above and below the $\mathrm{LH}$, for the red color is $22.5^{\circ}$, for blue is $40^{\circ}$, for yellow is $47.5^{\circ}$ and for white is $55^{\circ}$.

In some cases it is necessary to rotate the head to achieve the appropriate visual field. In this case, the head can be rotated an angle of 30 degrees front or back, which is considered a normal inclination.

To look a traffic sign above, the head can be rotated back into the maximum value of 50 degrees. To look a sign below, the head is rotated front the maximum of 50 degrees. Achieving the maximum viewing of the red color $\left(22.5^{\circ}\right)$ implies the rotation of the eye upwards. The white color has an ideal field of vision of 45 to $60^{\circ}$ for reading.

Therefore, the image analysis was used to understand the responses of the eight respondents who reported difficulty in the rapid assimilation of the texts of the signs. This was due to the angle of vision that brings the discomfort they have commented.

It was also found that the greater the distance from the viewer to the street name sign, the worse the readability of text. This happens due to font type and the color selected to contrast with the sign background (Figure 2).

\subsection{Positive and negative points}

Positive points: different background color in relation to visual elements, but the combination of colors is not adequate in both traffic and street name signs. So, contrast will be studied because its influence is more important than the lighting for readability.

Negative points: problems with the readability of typography in terms of type, shape, size and color. Contrast applied to the background and font used in the street name sign.

\subsection{Analysis and discussion}

The color is investigated with the other elements that accompany it such as the sign shape, the size of its background, the typography and the pictogram.

However, the colors of traffic signs cannot be changed due to rules already established by traffic codes, but the typography can be evaluated and reviewed.

According to Guimarães [10], the colors are an important visual stimulus, whereas its use requires caution because of the number of people, mostly men (about $8 \%$ of men), which have some difficulty in color perception.

For Otl [3], nowadays visual graphic symbols along with words are converted into means of understanding.

The traffic and street name signs analyzed had readability problems in relation to text, pictograms and recognition in distance. Another problem of readability was the blue background and white typography in the street name signs. Respondents considered adequate the form and size of signs.

There were suggestions to change the type of material, style and color of the sign support, to use adhesive and paint for the letter and pictogram.

To have a color recognition without moving the head, it is necessary to see the signs with greater distance, however the font types of the signs will get smaller and illegible. The yellow color has a larger visual field, so its use is recommended.

\subsection{Project development}

To improve the legibility of street name and traffic signs, a comparison in terms of typography is made.

It was noticed that some font formats generate confusion, taking more time to assimilate the information.

Some examples of letters with this problem: $\mathrm{O}$ and $\mathrm{Q}, \mathrm{T}$ and $\mathrm{Y}, \mathrm{S}$ and $5, \mathrm{I}$ and $\mathrm{L}, \mathrm{X}$ and $\mathrm{K}, \mathrm{I}$ and $\mathrm{1}, \mathrm{O}$ and 0 (zero), $\mathrm{C}$ and $\mathrm{G}, \mathrm{D}$ and $\mathrm{B}, \mathrm{H}$ and $\mathrm{M}$ and $\mathrm{N}, \mathrm{J}$ and $\mathrm{T}$ and $\mathrm{I}, \mathrm{K}$ and $\mathrm{R}, 2$ and $\mathrm{Z}, \mathrm{B}$ and $\mathrm{R}, \mathrm{S}$ and 8 .

A typographical setting was performed in relation to shape, size and color. The colors were studied for the letters according to the background color, with respect to contrast based on the visual field of the comfort zone.

Color blind users were taken into account, which confuse certain colors, decreasing the effectiveness of contrast when compared to a standard user.

There was a concern about the pictograms, since the visual image is assimilated better than textual information.

\subsection{Interviews with users}

A quantitative and qualitative questionnaire was conducted with eight new respondents, showing signs of the city, focusing on the visual and efficiency.

These respondents are a new group, different from the participants of the item 3.1. The choice of a new group follows the proposal of Malhotra [14]. 
Figure 3 shows a street name sign, in which deficiencies of readability were detected. To get more information for the research, respondents were asked to assign a degree of importance to the visual elements that are part of the sign, according to the first thing they visualize.

The level of information was measured in relation to aspects: (i) color, (ii) format, (iii) typography, (iv) pictogram.
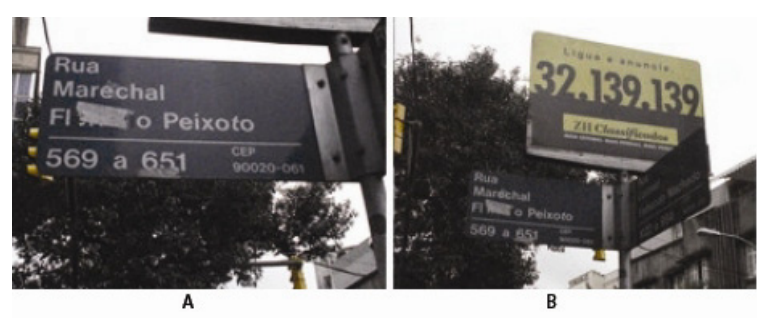

Fig. 3: Street name sign

In Figure 3-A, $100 \%$ of the respondents reported that the color is the first viewing, knowing that the color blue represents the street name signs. In order of importance, $100 \%$ responded Color in the first place, Typography in the $2 \mathrm{nd}$, Pictogram in the $3 \mathrm{rd}$ and Format in the 4th.

In Figure 3-B, $100 \%$ of the respondents also reported that color is the first viewing. Attention was more to the advertising sign than to the street name sign. In order of importance, $100 \%$ responded: 1 st Color, 2nd Typography, 3rd Pictogram and 4th Format.

In Figure 6-A, the respondents observed that the traffic sign has a text difficult to read due to the shape and weight. A $100 \%$ of the respondents said that the degree of information importance was: 1st Color, 2nd Pictogram, 3rd Typography and 4th Format.

\subsection{New proposal of signs and project adjustments}

After the new proposal of signs, this study had two important adjustments: (i) the background color of the sign, (ii) color identification of neighborhoods.

The background color of the sign was chosen based on the responses to the questionnaire that considered the color black as too dark and the blue color better, in spite of the stronger contrast of black and yellow. Figure 4 presents the new street name sign and the adjustment of background color.
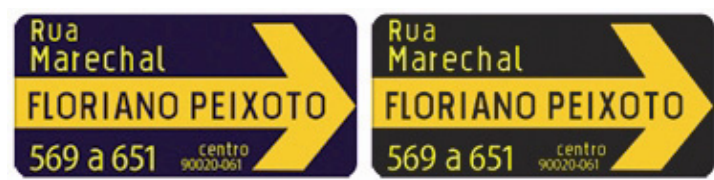

Fig. 4: New street name sign with background color

To identify areas of Porto Alegre city, the color below the arrow of the sign is modified according to the neighborhood (Figure 5).

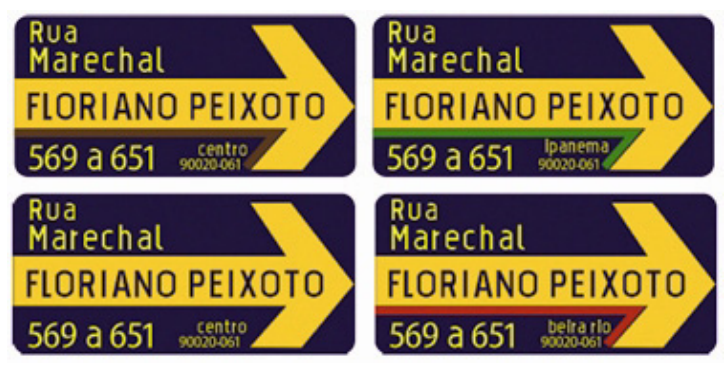

Fig. 5: Color by areas in the new street name sign

On traffic signs, colors cannot be changed. Hence the typography was changed to promote greater legibility at distance (Figure 6).

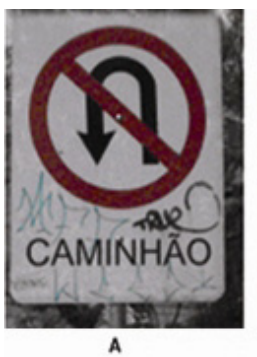

A

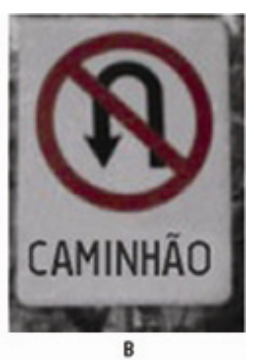

Fig. 6: Traffic sign. (A) Nowadays. (B) New typography.

\subsection{Virtual simulation}

A virtual simulation of the "Street of Antiques" was made and presented to the respondents to collect the perception of the final result (Figure 7).

$100 \%$ of respondents considered the result as pleasant, and said it is possible to identify the street through color and support style.

To complete the methodology, new adjustments to the project are made until the satisfaction of respondents is achieved. 


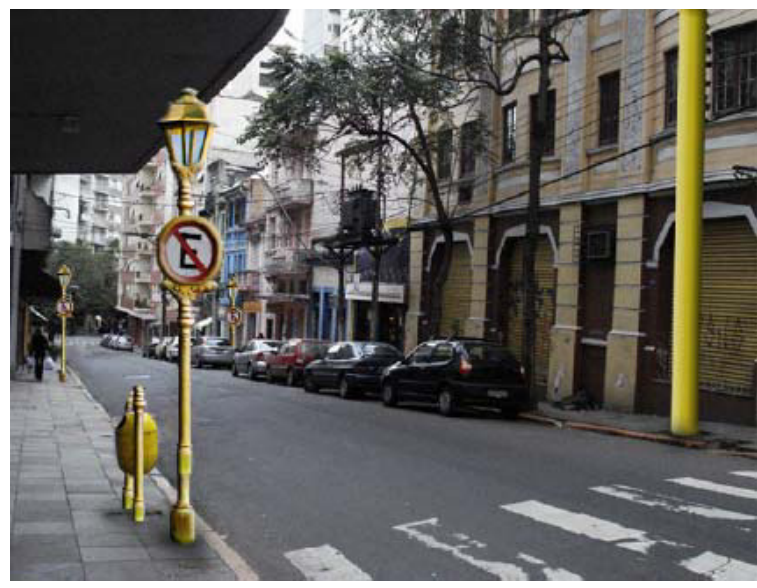

Fig. 7: Virtual simulation

\subsection{Implementation and supervision}

The monitoring of projects is performed to avoid errors in production, especially in the adhesive colors of the signs, typography and layout of visual elements. The installation of the supports should be checked to verify their height.

\section{Results}

The results of data collection showed the need for adjustments on the traffic and street name signs in the following aspects: color, typography and layout.

These adjustments were important to improve readability and comprehensibility for different types of users. Analyses were performed with adult pedestrians, but the same steps can be applied for other audiences: driver, passenger, cyclist and motorcyclist.

\section{Conclusions}

Studies of cognitive ergonomics, specifically in the visual field and color recognition, contribute to the improvement of traffic and street name signs.

The results obtained contribute to the development of this type of urban furniture. Thus, it is proposed that this study become a reference material for designers.

Now color is no longer seen only as an aesthetic element, because it has an importance in the project and helps functionality of signs, bringing user satisfaction.

\section{Acknowledgments}

The authors would like to thank CNPq Brazilian Research Agency for financial support obtained through the announcement MCT/CNPq 14/2010Universal.

\section{References}

[1] A. Moraes (org.), Avisos, Advertências e Projeto de Sinalização: Ergodesign. Rio de Janeiro: Iuser, 2002.

[2] A. Moraes (org.). In: Ergodesign do Ambiente Construído e Habitado: Ambiente Urbano, Ambiente Público, Ambiente Laboral Iuser, 2004.

[3] A. Otl and M. Krampen, Sistemas de signos em La comunicación visual: manual para diseñadores, arquitectos, planificadores y analistas de sistemas. México: Ediciones G. Gili, S. A. de C. V., 1991.

[4] B. Löbach, Design Industrial: Bases para a configuração dos produtos industriais. São Paulo: Editora Edgard Blücher, 2001.

[5] D. D'Agostini and L. A. V. N. Gomes, Design de Sinalização: planejamento, projeto \& desenho. Porto Alegre: Ed. UniRitter, 2010

[6] G. Bonsiepe, Design, Cultura e Sociedade. São Paulo: Blücher, 2011.

[7] H. Dreyfuss, As Medidas do Homem e da Mulher: Fatores Humanos em Design. Porto Alegre: Bookman, 2005.

[8] I. Iida, Ergonomia - Projeto e Produção - $2^{\mathrm{a}}$ Edição, Editora Edgard Blücher, 2005.

[9] J. Panero, Las dimensiones humanas en los espacios interiors. 1. Ed. Barcelona: G.G., 1983. 320p.

[10] L. B. M. Guimarães, Ergonomia Cognitiva: Processamento da Informação, erro humano IHC. Porto Alegre: FEENG/UFRGS/EE/PPGEP, 2001.

[11] M. Bauer and G. Gaskell, Pesquisa Qualitativa com Texto, Imagem e Som: Um manual prático. Rio de Janeiro: Vozes, 2000 .

[12] M. Baxter, Projeto de Produto: Guia prático para o design de novos produtos. 2a .Ed. São Paulo: Edgard Blücher, 2008.

[13] M. Montmollin, A ergonomia. Lisboa : Piaget, 1995.

[14] N. K. Malhotra, Pesquisa de marketing: uma orientação aplicada. Porto Alegre: Bookman, 2000. 